\title{
Cannabinoid Hyperemesis Syndrome; A Growing Concern for New Mexico
}

\author{
Victoria F Dirmyer* \\ Department of Health, Mexico
}

Submission: August 10, 2018; Published: October 09, 2018

"Corresponding author: Victoria F Dirmyer, PhD, New Mexico Department of Health, Health Systems Epidemiology Program, 1190 St. Francis Dr., Suite S3400, Santa Fe, NM, 87502, Mexico, Tel: 505-476-3572; Fax: 505-827-2110; Email: vcfriedel@gmail.com

Abstract

Background: In 2012, New Mexico became the 12th state to allow the use of cannabis for medical use. Cannabinoid hyperemesis syndrome (CHS) is characterized by recurrent episodes of heavy nausea, vomiting, and abdominal pain. Early identification of patients with CHS will assist in decreasing orders for invasive and expensive medical procedures.

Methods: A retrospective analysis was performed using emergency department (ED) data from 2010-2015 in New Mexico. CHS was defined as an ED visit with a combination of persistent vomiting and cannabis related diagnosis codes. Trends over the six years were analyzed by patient characteristics; sex, age, and geographic location, as well as overall counts of visits for this health condition. A weighted national estimate using the Nationwide Emergency Department Sample (NEDS) was used as a comparison to New Mexico state data.

Results: The overall number of ED visits increased by $24.2 \%$ from 2010 to 2015. The annual number of ED visits for CHS increased by $585.7 \%$ in New Mexico. In the U.S., a similar increase in CHS was observed at 423.3\%. In New Mexico, CHS visits were more likely to be male, between the age of 18-29 years, and reside in the northeast region of the state.

Conclusion: This analysis demonstrated that ED visits for CHS are increasing and as more states adopt recreational marijuana use legislation, larger increases will be observed.

Keywords: Cannabis; Emergency department; Cyclic vomiting; Hot showers

\section{Introduction}

Marijuana is the most commonly used illicit drug in the United States (22.2 million people have used it in the past month) according to the 2015 National Survey on Drug Use and Health [1]. Marijuana use is more prevalent among males compared to females and more likely to be used by adolescents and young adults. [2]. The overall prevalence of marijuana use has remained stable in the United States at $4 \%$, but the prevalence of cannabis related disorders has continued to increase [3]. As of December 2016, more than half of all states in the United States have a law legalizing marijuana for recreational or medical use. [4]. In 2007, New Mexico became the 12th state to allow the use of cannabis for medical use with the Lynn and Erin Compassionate Use Act.

Cannabinoid Hyperemesis Syndrome (CHS) was first described in 2004 by Allen and colleagues [5], and is characterized by chronic cannabis use, cyclic episodes of nausea and vomiting, and the learned behavior of hot bathing [5,6]. Several case reports have described patients with chronic marijuana use presenting to healthcare facilities with abdominal pain, cyclic vomiting, and compulsive showering [7-15], but there are few epidemiologic studies that have analyzed the association between marijuana use and CHS.
In this analysis, emergency department data from 2010-2015 was analyzed for CHS cases. The primary objective of this study was to describe the prevalence of CHS over a 6-year period in New Mexico. A secondary objective was to compare any CHS trends observed in New Mexico to national estimates.

\section{Materials and Methods}

\section{Study Sample and Variables}

This study is a retrospective analysis of emergency department (ED) data from hospitals across the state of New Mexico. This data consists of ED visits from 36 non-federal hospitals. Data elements included in this dataset include patient characteristics including age, sex, and patient residence information as well as visit characteristics including +/- 20 diagnosis fields, + /- 6 procedures codes (2015 only) and visit and discharge information (dates and times).

Six years of New Mexico ED data were analyzed (2010-2015) with an average of 765,000 visits per year. For this analysis, the following ICD-9-CM and ICD-10-CM codes were used: Cannabis Related Diagnosis Codes [ICD-9-CM: 304.3, 304.30, 304.31, 
305.20, 305.21; ICD-10-CM: F12.10, F12.2, F12.20, F12.9, F12.90] and Persistent Vomiting [ICD-9-CM: 536.2; ICD-10-CM: R11.10]. A CHS case was defined as an ED visit with a cannabis related diagnosis code and a persistent vomiting diagnosis code.

\section{National Study Sample}

For national estimates of ED visits, five years of emergency department data were analyzed (2010-2014) using the Nationwide Emergency Department Sample (NEDS), Healthcare Cost and Utilization Project (HCUP), Agency for Healthcare Research and Quality. (Healthcare Cost and Utilization Project (HCUP), 2017) The NEDS dataset contains ED data from 30 states with approximately 30 million ED visits each year. The NEDS dataset can be weighted to yield national estimates [16].

\section{Results}

The annual number of total ED visits increased by $24.2 \%$ from 2010 to 2015 in New Mexico. During this six-year period, the annual number of ED visits for cannabis increased by $172.8 \%$ and $585.7 \%$ for CHS visits (Table 1). On the national level, total estimated ED visits increased 6.9\% from 2010 to 2014 (same period in New Mexico saw a 23.6\% increase). National estimates for cannabis ED visits increased $71.9 \%$ and CHS increased $423.3 \%$

Table 1: Annual Number of ED Visits and Patient Counts for Cannabis and CHS for NM Residents, 2010-2015

\begin{tabular}{|c|c|c|c|c|}
\hline & $\begin{array}{c}\text { Prevalence of CHS (per 100,000 } \\
\text { ED Visits) }\end{array}$ & $\begin{array}{c}\text { Number of } \\
\text { CHS Visits }\end{array}$ & $\begin{array}{c}\text { Number of Patients with } \\
\text { CHS Visits }\end{array}$ & $\begin{array}{c}\text { Number of Visits for Cannabis Only Among CHS } \\
\text { Patients* }\end{array}$ \\
\hline 2010 & 2.13 & 14 & 10 & 8 \\
\hline 2011 & 4.64 & 33 & 21 & 10 \\
\hline 2012 & 5.19 & 38 & 24 & 23 \\
\hline 2013 & 6.05 & 47 & 33 & 19 \\
\hline 2014 & 5.18 & 42 & 34 & 14 \\
\hline 2015 & 11.79 & 96 & 88 & 50 \\
\hline
\end{tabular}

*This represents visits in addition to the CHS visits for the same patients.

In New Mexico, a higher percentage of CHS visits were among males, between the age of 18-29 years, who resided in the Northeast region of the state. A higher percentage of visits for cannabis were male, between the age of 30-64 years, who resided in the Northeast region of the state. For every year of ED analysis, all four age groups (0-17, 18-29, 30-64, and 65+ years) had an increase in the number of visits for cannabis. On a national level, a higher percentage of CHS visits were male and between the age of 30-64 years. Visits for cannabis followed a similar pattern.
The number of visits for cannabis have been steadily increasing from 2010-2015, with a very large increase from 2014-2015 (Figure 1). A similar trend was observed for CHS visits. Visits for vomiting decreased in 2012, but then increased from 2013-2015, with a similar large increase from 2014-2015 as observed for both cannabis and CHS visits. The number of patients admitted for CHS increased with each year (Table 1). On average, each patient visited 1.5 times for CHS. Evaluating CHS and cannabis only visits together, patients visited roughly 2 times per year (the range was $0-5$ additional visits).

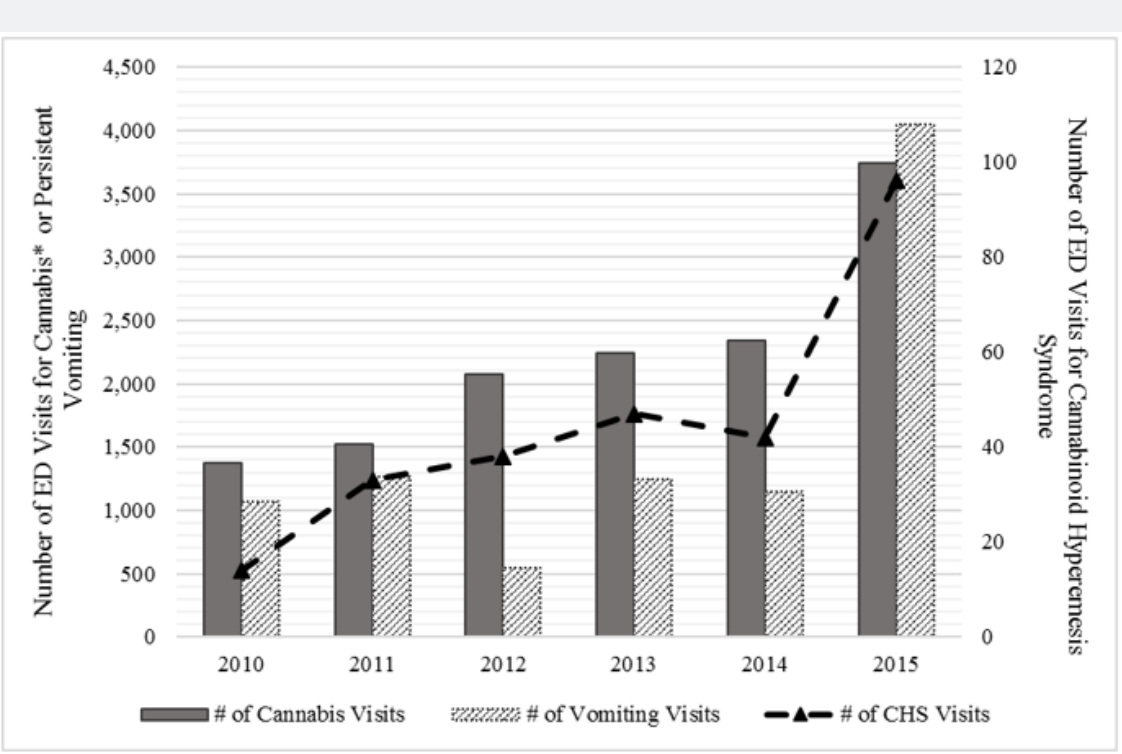

Figure 1: Annual Number of ED Visits for Cannabis, Persistent Vomiting, and CHS for NM Residents, 2010-2015. 


\section{Discussion}

\section{Key Findings}

In this analysis, we found that the number of ED visits for patients presenting with CHS symptoms has increased from 2010 to 2015 . Both the number of patients per year and the number of visits has increased, with an average of 1.5 annual visits per patient. A higher percentage of patients presenting with CHS symptoms were male and between the age of 18-29 years. New Mexico CHS patients differ from national CHS patients as New Mexico patients are younger in age.

The New Mexico Medical Cannabis program (MCP) has grown substantially. In 2012, the number of active patients in the MCP was 8,059 New Mexico residents. At the end of 2015, the number of active, purchasing members grew to $41,419 \mathrm{New}$ Mexico residents (https://nmhealth.org/about/mcp/svcs/pdb/). A lot of the growth in MCP members is due to increased efficiency in processing MCP registrations, additional health conditions added to the list of qualifying conditions, and increased supply of cannabis due to the addition of more licensed producers.

In an analysis of ED visits from two large Colorado hospitals from 2008-2011, Kim et. al [17], found that the prevalence of cyclic vomiting ED visits doubled after marijuana liberalization in the state. Of the patients admitted for cyclic vomiting, marijuana use was more likely documented after medical cannabis use legislation went into effect (October 19, 2009). Cyclic vomiting and CHS are very similar syndromes with the main difference being a history of cannabis use among CHS patients [18]

The increase in the number of visits for CHS is concerning as this may just be the tip of the iceberg regarding ED visit numbers. Studies have shown that there is a delay in the onset of vomiting illness in chronic cannabis users. The delay could be 1-2 years before a CHS patient experiences heavy nausea, vomiting, and abdominal pain. Hot showering or bathing can bring temporary relief to CHS patients, but only cessation of cannabis use will cure the patient $[18,19]$. Those patients that return to chronic cannabis use after a period of cessation have the potential for relapse. Not all chronic users of cannabis will develop CHS [19].

Most likely the national estimate is an underestimate of the number of visits for both cannabis and CHS. Of the 30 states that participate in NEDS, Colorado and Washington are not included. Both states have recreational marijuana laws that went into effect in 2012. Of the 9 jurisdictions that have recreational marijuana laws (Alaska, California, Colorado, Maine, Massachusetts, Nevada, Oregon, Washington, and Washington D.C) only Colorado and Washington had laws that were enacted prior to 2015. Of the 29 jurisdictions that have medical marijuana laws, only 16 are included in the NEDS dataset and had laws enacted prior to 2015. Key states are missing from the NEDS dataset that would be influential in estimating the national prevalence of CHS.

\section{Limitations}

There are a few limitations for this study. First, this is a retrospective study of emergency department data. The data was not collected for analyzing CHS prevalence. Second, CHS cases were identified by ICD-9-CM codes alone, and there is not a specific ICD9-CM code that identifies CHS. Other studies have used medical records and doctor's notes to identify CHS patients; access to these data sources was not available for this analysis. Third, other factors, in addition to the legalization of medical marijuana, could play a role in the observed increase in CHS over time. Fourth, a greater awareness of CHS by physicians' over time could explain some of the observed increase in CHS. Lastly, the collection of emergency department data started in 2010, therefore it is not possible to analyze CHS prior to or directly after legalization of medical cannabis in New Mexico.

\section{Conclusion}

Currently cannabis is only available to individuals with a medical need in New Mexico, but Colorado permits New Mexico residents to purchase cannabis in Colorado. Several states are moving to recreational use of cannabis and more states could adopt recreational use legislation. With the increasing availability and potential relaxing of legal restrictions on cannabis, recognition of CHS patients by healthcare staff is paramount to reducing healthcare costs. Diagnosing CHS can be hard as persistent vomiting with no clear cause necessitates multiple expensive and invasive medical procedures. Education of healthcare personnel will assist with identifying and treating CHS patients, which will ultimately lower healthcare costs.

\section{Acknowledgement}

The author thanks Dr. Michael Landen (New Mexico Department of Health) for this guidance on the research approach, methodology, and manuscript review.

\section{Conflict of Interest}

The author declares no conflict of Interest.

\section{References}

1. SAMHSA, CBHSQ Results from the (2015) National Survey on Drug use and Health: Detailed Tables.

2. Carliner H, Mauro PM, Brown QL, Shmulewitz D, Rahim Juwel R, et al. (2017) The Widening Gender Gap in Marijuana use Prevalence in the U.S. During a Period of Economic Change. Drug Alcohol Depend 170: 51-58.

3. Compton WM, Grant BF, Colliver JD, Glantz MD, Stinson FS (2004) Prevalence of Marijuana use Disorders in the United States. JAMA 291(17): 2114-2121.

4. Schauer GL, King BA, McAfee TA (2017) Prevalence, Correlates, and Trends in Tobacco use and Cessation Among Current, Former, and Never Adult Marijuana Users with a History of Tobacco Use. Addict Behav 73: 165-171. 
5. Allen JH, de Moore GM, Heddle R, Twartz JC (2004) Cannabinoid Hyperemesis: Cyclical Hyperemesis in Association with Chronic Cannabis Abuse. Gut 53(11): 1566-1570.

6. Galli JA, Sawaya RA, Friedenberg FK (2011) Cannabinoid Hyperemesis Syndrome. Curr Drug Abuse Rev 4(4): 241-249.

7. Wallace D, Martin AL, Park B (2007) Cannabinoid Hyperemesis: Marijuana Puts Patients in Hot Water. Australas Psychiatry 15(2): 156158.

8. Chepyala P, Olden KW (2008) Cyclic Vomiting and Compulsive Bathing with Chronic Cannabis Abuse. Clin Gastroenterol Hepatol 6(6): 710712.

9. Singh E, Coyle W (2008) Cannabinoid Hyperemesis. Am J Gastroenterol. 103: 1048-1049.

10. Sontineni SP, Chaudhary S, Sontineni V, Lanspa SJ (2009) Cannabinoid Hyperemesis Syndrome: Clinical Diagnosis of an Underrecognised Manifestation of Chronic Cannabis Abuse. World J Gastroenterol 15(10): 1264-1266.

11. Soriano Co M, Batke M, Cappell MS (2010) The Cannabis Hyperemesis Syndrome Characterized by Persistent Nausea and Vomiting, Abdominal Pain, and Compulsive Bathing Associated with Chronic Marijuana Use: A Report of Eight Cases in the United States. Dig Dis Sci 55(11): 3113-3119.

12. Patterson DA, Smith E, Monahan M, Medvecz A, Hagerty B, et al. (2010) Cannabinoid Hyperemesis and Compulsive Bathing: A Case Series and

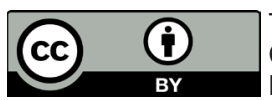

This work is licensed under Creative Commons Attribution 4.0 License DOI: 10.19080/ASM.2018.02.555577
Paradoxical Pathophysiological Explanation. J Am Board Fam Med 23(6): 790-793.

13. Donnino MW, Cocchi MN, Miller J, Fisher J (2011) Cannabinoid Hyperemesis: A Case Series. J Emerg Med 40(4): e63-6.

14. Simonetto DA, Oxentenko AS, Herman ML, Szostek JH (2012) Cannabinoid Hyperemesis: A Case Series of 98 Patients. Mayo Clin Proc 87(2): 114-119.

15. Nicolson SE, Denysenko L, Mulcare JL, Vito JP, Chabon B (2012) Cannabinoid Hyperemesis Syndrome: A Case Series and Review of Previous Reports. Psychosomatics 53(3): 212-219.

16. Healthcare Cost and Utilization Project (HCUP) (2017) HCUP Nationwide Emergency Department Sample (NEDS). Agency for Healthcare Research and Quality. Rockville, USA.

17. Kim HS, Anderson JD, Saghafi O, Heard KJ, Monte AA (2015) Cyclic Vomiting Presentations Following Marijuana Liberalization in Colorado. Acad Emerg Med 22(6): 694-699.

18. Blumentrath CG, Dohrmann B, Ewald N (2017) Cannabinoid Hyperemesis and the Cyclic Vomiting Syndrome in Adults: Recognition, Diagnosis, Acute and Long-Term Treatment. Ger Med Sci 15: Doc06.

19. Richards JR, (2017) Cannabinoid hyperemesis syndrome: A Disorder of the HPA Axis and Sympathetic Nervous System? Med Hypotheses 103: 90-95.

\begin{tabular}{l} 
Your next submission with Juniper Publishers \\
will reach you the below assets \\
- Quality Editorial service \\
- Swift Peer Review \\
- Reprints availability \\
- E-prints Service \\
- Manuscript Podcast for convenient understanding \\
- Global attainment for your research \\
- Manuscript accessibility in different formats \\
( Pdf, E-pub, Full Text, Audio) \\
- Unceasing customer service \\
Track the below URL for one-step submission \\
https://juniperpublishers.com/online-submission.php \\
\hline
\end{tabular}

